\title{
Erratum to: A review of $\alpha$-amylase inhibitors on weight loss and glycemic control in pathological state such as obesity and diabetes
}

\author{
Mahmood Najafian
}

Published online: 16 September 2014

(C) Springer-Verlag London 2014

Erratum to: Comparative Clinical Pathology

DOI 10.1007/s00580-014-1967-x

The original version of this article contained a mistake on the name of the author. Instead of Najafian Mahmood it should be Mahmood Najafian.

The online version of the original article can be found at doi:10.1007/ s00580-014-1967-x.

M. Najafian ( $\bowtie)$

Department of Biology, Jahrom Branch, Islamic Azad University,

Jahrom, Iran

e-mail: d.najafian@jia.ac.ir 